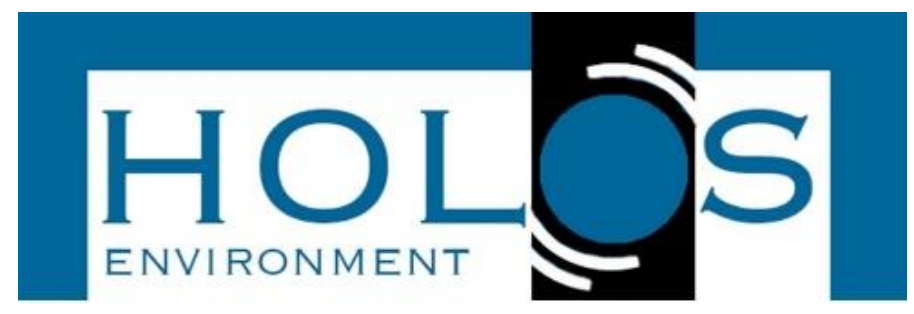

\title{
CARACTERIZAÇÃO DA QUALIDADE DA ÁGUA SUBTERRÂNEA UTILIZANDO ÍNDICES DE QUALIDADE DA ÁGUA EM RIACHÃO DO JACUÍPE, BAHIA
}

\section{GROUNDWATER QUALITY CHARACTERIZATION USING WATER QUALITY INDEXES IN RIACHÃO DO JACUÍPE, BAHIA}

\author{
Rosa Alencar Santana de Almeida1; Lorenzo Guimarães de Mello
}

Artigo recebido em: 11/06/2019 e aceito para publicação em: 22/11/2019.

DOI: http://dx.doi.org/10.14295/holos.v19i4.12346

\begin{abstract}
Resumo: A água subterrânea representa uma crucial fonte para abastecimento de comunidades rurais nas regiões semiáridas. A escassez hídrica, relatada em diversos estudos prévios, exige que sejam conhecidas e divulgadas informações sobre a qualidade da água disponível, como uma das formas para melhor gerir e conservar as reservas existentes. O principal objetivo deste trabalho foi caraterizar as águas de poços profundos na região de Riachão do Jacuípe (BA), por meio de Índices de Qualidade de Água (IQA), com a finalidade de dispor, aos moradores, gestores e tomadores de decisão, um recurso para informar, de maneira simples, a qualidade da água fornecida à comunidade. A pesquisa também investigou os usos e tratamento dispensados à água, com o intuito de sugerir medidas para corrigir possíveis carências. Para esses propósitos foram utilizados resultados de análises de água fornecidos pela Secretaria do Meio Ambiente (BA) e entrevistas junto à comunidade. Esta pesquisa é uma contribuição importante para compreender a relação entre a qualidade da água e a situação de vulnerabilidade das comunidades rurais do semiárido. Os objetivos foram alcançados com o uso de três metodologias de cálculo de índices de qualidade de água (IQA): IQA CETESB, CCME WQI e eIQUAS, aplicadas para doze amostras de água, para as quais foram avaliados vinte parâmetros. Os resultados mostraram convergência na caracterização estabelecida nas três metodologias, todas as amostras foram classificadas como "ruins". A aplicação de índices se mostrou adequada, todavia tais mecanismos devem ser associados a outros recursos de avaliação. Quanto ao senso dos usuários, os resultados sugerem que os moradores precisam conhecer melhor a relação entre a qualidade da água com possíveis riscos para a saúde. A disseminação dos Índices de qualidade de água pode ser um mecanismo eficaz, oportunizando a população, gestores e decisores determinarem ações para mitigar as carências percebidas.
\end{abstract}

Palavras-chave: Índice de qualidade de água. Água para consumo humano. Água no semiárido. Água subterrânea. Comunidades tradicionais.

\begin{abstract}
Groundwater represents a most important resource for supplying rural communities in semiarid regions. Water scarcity, reported in papers, requires that available information on water quality are knewn and disseminated as one ways to manage and conserve existing reserves. The main objective of this study is to characterize deep wells' waters of Riachão do Jacuípe (BA) region, by means of Water Quality Indexes (WQI), in order to provide the residents, managers and decision makers, a simple way to inform the water quality provided to the community. The study also investigated the uses and water treatment, in order to suggest measures for mitigate possibles failures. For these purposes, the results of water analyzes provided by the Secretaria do Meio Ambiente do Estado da Bahia and the community surveys with the is used. This paper is an relevant contribution for understanding the relationship between water quality and the vulnerability of rural communities in the semi-arid region. These goals has been achieved with the use three methodologies of Water Quality Indexes (WQI): IQA CETESB,
\end{abstract}

\footnotetext{
${ }^{1}$ Universidade Federal do Recôncavo da Bahia (UFRB), Cruz das Almas, Bahia. E-mails: (rosaalencar@ufrb.edu.br, lorenzogmello@gmail.com)
} 
CCME WQI e-IQUAS, applied to twelve water samples, for which were evaluated twenty parameters. The results showed convergence in the characterization established in the three methodologies, all the samples were classified as "bad". The application of indexes proved to be adequate, however it was acknowledged that such mechanisms should be associated with other evaluation resources. As for users' feeling to water access, the results suggest that residents need better to know the relationship between water quality and possible health risks. The dissemination of water quality indexes can be an effective mechanism in this task, allowing the population, managers and decision makers determine actions to mitigate the deficiencies perceived.

Keywords: Water quality index. Drinking water. Water in semi-arid region. Groundwater. Traditional communities.

\section{INTRODUÇÃO}

No Nordeste brasileiro, os problemas sociais e econômicos são mais acentuados do que em outras áreas do Brasil. E um destes problemas está diretamente relacionado com a disponibilidade hídrica na região. $O$ déficit hídrico vem se agravando, principalmente na região semiárida, e segundo dados sobre a conjuntura de recursos hídricos, a situação de seca se intensificou nos últimos anos registrando pico em dezembro de 2016, quando a maior parte da região se encontrava em condição de seca excepcional (ANA, 2018). De acordo com a Agência Nacional de Águas (ANA, 2018) para enfrentar essa questão são elaborados termos de alocação negociada da água e estabelecidas regras de restrição de uso de água, buscando preservar e prolongar a disponibilidade hídrica, e estabelecendo a prioridade para consumo humano e dessedentação de animais.

A água subterrânea em muitas regiões, especialmente em áreas áridas $\mathrm{e}$ semiáridas, é um suprimento substancial de água (SADAT-NOORI; EBRAHIMI; LIAGHAT, 2013). Em 2007, pesquisas da ANA sugeriam que a água subterrânea representava a principal fonte para comunidades rurais no semiárido brasileiro, embora o órgão compreendesse que, ainda eram escassos os estudos e informações sobre a qualidade das águas subterrâneas na região, por falta de rede de monitoramento ou pela sistematização dos dados, muitas vezes inexistentes (ANA, 2007).

$\mathrm{Na}$ conjuntura atual, as soluções alternativas por meio de poços continuam sendo utilizadas e as informações seguem insuficientes. Em Julho de 2018, de acorodo com dados da ANA (2018) existiam 302 mil poços cadastrados no Brasil, embora uma nova projeção indicasse 1,2 milhão de poços tubulares no país. No mesmo ano a agência contabilizou apenas 394 poços de monitoramento (ANA, 2018). 
Portanto, diante da perspectiva de escassez e degradação dos corpos hídricos, e da premência por informações, se faz indispensável a interpretação eficiente dos dados existentes e a disseminação das pesquisas sobre a qualidade da água disponível.

Para conhecer a qualidade das águas são utilizadas análises das caracteríticas físico-químicas e bacteriológicas. Os resultados são complexos, compreendem inúmeros parâmetros que normalmente são sistematizados para divulgação na forma de relatórios. Em geral esses instrumentos são muito detalhados e técnicos, mas que não fornecem uma avaliação abrangente da qualidade da água (HAMDAN; DAWOOD; NAEEM, 2018).

Para responder a essa questão, ou seja, para facilitar a comunicação dos resultados ao público não técnico, desenvolveram-se os índices de qualidade de água (IQA). Os IQA's integram variáveis de qualidade de água em um único número, que exprime a qualidade do compartimento hídrico analisado. $O$ índice é um número adimensional que varia entre 0 e 100 , sendo que o maior valor sugere melhor qualidade da água.

Os primeiros índices foram propostos na segunda metade do século $X X$ (HORTON, 1965; BROWN et al., 1970; DEININGER, 1971; DINIUS, 1972; CETESB, 1975). Essas formulações acompanhavam a desatenção com a deterioração ambiental e não incorporavam a presença de substâncias químicas associadas a atividades humanas. Já na primeira década do século XXI, surgiram iniciativas que incorporam as preocupações com os impactos das atividades humanas. Tem-se como exemplos: o ISTO, desenvolvido pela CETESB e destinado às águas superficiais (CETESB, 2019), e o SEQ ESO Système d'Évaluation de la Qualité - Eaux Souterraines (CADILHAC E ALBINET, 2003); o IQASB (ALMEIDA, 2007), e o eIQUAS (ALMEIDA, 2012), voltados ao compartimento subterrâneo.

Percebe-se a importância dos índices, entretanto, depreende-se que os métodos para novas formulações devem ser consistentes, reprodutíveis e ter suas limitações claramente documentadas. Ademais, são ferramentas complementares, que devem ser associadas a outras modalidades de controle e monitoramento para avaliação completa do recurso. Tomas, Curlan e Maric (2017) ressaltam que o uso dos IQA's simplifica a comunicação, mas deve ser associado a outras técnicas para identificação de fatores e influências na qualidade da água. 
Esta pesquisa apresenta a caracterização da qualidade da água fornecida às comunidades rurais de Riachão do Jacuípe (BA), baseada na aplicação de três diferentes índices de qualidade de água (IQA), como também retrata o senso dos moradores sobre a utilização da água disponível. Para esse propósito, foram usados dados secundários de análises de águas coletadas em poços da região, e foram realizadas investigações complementares sobre usos e tratamento dispensados à água.

\section{2 ÁREA DE ESTUDO}

O município de Riachão do Jacuípe tem área territorial de $1.190 \mathrm{~km}^{2}$. Localizase na bacia hidrográfica do Rio Paraguaçu e na sub-bacia do Rio Jacuípe, tributário do Paraguaçu, sendo este o principal curso d'água da região (PEMAPES, 2011). O clima da região é o semiárido, o município está localizado na área denominada de "Polígono das Secas", destacada por sofrer longos períodos de estiagem (SERVIÇO GEOLÓGICO DO BRASIL, 2005).

O território encontra-se em dois domínios hidrogeológicos que possuem características e comportamento de aquífero fissural, ou seja, em circunstâncias de presença de água subterrânea a mesma é condicionada por meio de porosidade secundária, que consiste em reservatórios aleatórios, descontínuos e de pequenas extenões (MME, 2005). Portanto, é frequente encontrar poços com baixas vazões. Além disso, tem-se importantes aspectos que interferem na qualidade: a baixa circulação, o contato com as rochas e o clima semi-árido. A combinação desses fatores costuma resultar em águas salinizadas (MME, 2005). Entretanto, essa característica não subtrai a importância do poço como fonte alternativa de abastecimento em comunidades rurais que não possuem sistemas convencionais de abastecimento.

\section{MATERIAIS E MÉTODOS}

\subsection{Dados de qualidade da água}

Foram utilizados dados do "Relatório de Teste de Bombeamento - № 124.885/2015", elaborado no âmbito do Programa Água Doce, da Secretaria do Meio 
Ambiente do Estado da Bahia, em uma ação que realizou 732 diagnósticos no estado (ITEP, 2015). São os resultados de ánalises realizadas em amostras de água coletadas em poços profundos na região de Riachão do Jacuípe, Bahia, no ano de 2015, efetuadas sob a responsabilidade do Instituto de Tecnologia de Pernambuco (ITEP). As amostras foram coletadas em 12 poços, conforme mostrado na Tabela 1 , nas quais foram analisados os parâmetros sugeridos no documento base do Programa Água Doce (SECRETARIA DE RECURSOS HÍDRICOS E AMBIENTE URBANO, 2012).

Para esse conjunto de dados foram calculados os três índices de qualidade da água descritos nesta pesquisa: IQA CETESB (CETESB, 2019), CCME WQI (CCME, 2001) e o e-IQUAS (ALMEIDA, 2012).

\subsection{Dados sobre a percepção dos moradores}

Para avaliar a percepção dos moradores face às condições de acesso a água, escolheu-se a comunidade cuja água recebeu a pior qualificação, de acordo com os três índices calculados.

Foram tomados os cuidados necessários para esclarecer os moradores sobre os objetivos da investigação. Antes da aplicação dos questionários, foram explicados os benefícios da pesquisa e informados sobre os riscos associados ao fornecimento das informações. Desta forma, como recomendam Rogers e Ballantyne (2008), foi possível tornar a população um parceiro ativo e igual, no planejamento e execução da pesquisa. O projeto foi submetido ao Comitê de Ética em Pesquisa com seres humanos (CEP) da Universidade Federal do Recôncavo da Bahia, e está registrado na Plataforma Brasil com o identificador do CAAE - Certificado de Apresentação para Apreciação Ética № 72507417.1.0000.0056. 
Tabela 1 - Resultados das análises em Poços Profundos das comunidades de Riachão do Jacuípe

(continuação)

\begin{tabular}{|c|c|c|c|c|c|c|c|c|c|c|}
\hline Localidade & $\begin{array}{c}\text { Alcalinidade } \\
\text { Total } \\
\text { mg/L CaCO3 }\end{array}$ & $\begin{array}{l}\text { Alumínio } \\
\text { Total } \\
\text { mg/L Al }\end{array}$ & $\begin{array}{l}\text { Amônia } \\
\text { mg/L NH3 }\end{array}$ & $\begin{array}{l}\text { Coliformes. } \\
\text { Termotolerantes } \\
\text { UFC/100MI }\end{array}$ & $\begin{array}{l}\text { Cloreto } \\
\mathrm{mg} \mathrm{Cl} / \mathrm{L}\end{array}$ & Cor & $\begin{array}{c}\text { Dureza } \\
\text { Total } \\
\mathrm{mg} / \mathrm{L} \\
\mathrm{CaCO3}\end{array}$ & $\begin{array}{l}\text { E. Coli } \\
\text { UFC/ } 100 \\
\text { ml }\end{array}$ & $\begin{array}{l}\text { Ferro } \\
\text { Total mg } \\
\text { Fe/L }\end{array}$ & $\begin{array}{c}\text { Fósforo } \\
\text { Total } \\
\text { mg P/L }\end{array}$ \\
\hline VIr Máximo Permitido & & 0,2 & 1,5 & Ausente & 250 & $15 \mathrm{uH}$ & & Ausente & 0,3 & \\
\hline Mandassaia II & 540,00 & 0,05 & 0,98 & Presença & 2782,00 & 5,0 & 1503,00 & Ausência & 0,05 & 1,36 \\
\hline Salgado & 452,00 & 0,05 & 6 & Presença & 1293,00 & 5,0 & 1975,00 & Presença & 0,05 & 0,37 \\
\hline Caldeirão Grande & 842,00 & 0,05 & 0,2 & Presença & 3332,00 & 5,0 & 582,00 & Ausência & 0,31 & 0,54 \\
\hline Bom Viver & 561,00 & 0,05 & 0,2 & Presença & 178,00 & 5,0 & 209,60 & Presença & 0,11 & 0,59 \\
\hline Ponto Novo & 726,00 & 0,05 & 0,2 & Presença & 2427,00 & 5,0 & 1740,00 & Presença & 0,10 & 0,27 \\
\hline Mandassaia I & 550,00 & 0,09 & 0,2 & Presença & 415,00 & 5,0 & 662,50 & Presença & 0,05 & 0,27 \\
\hline Poções/Capinas & 384,50 & 0,05 & 0,2 & Presença & 6600,00 & 5,0 & 5575,00 & Ausência & 0,05 & 0,23 \\
\hline Baixa Nova & 372,50 & 0,05 & 0,2 & Presença & 3473,00 & 10,0 & 3936,00 & Presença & 0,92 & 0,11 \\
\hline São Francisco & 350,50 & 0,05 & 0,2 & Presença & 4918,00 & 5,0 & 3922,00 & Ausência & 0,05 & 0,30 \\
\hline Onça & 460,00 & 0,05 & 0,2 & Presença & 8060,00 & 5,0 & 3591,00 & Presença & 0,17 & 0,66 \\
\hline Licuri & 660,00 & 0,57 & 0,2 & Presença & 518,00 & 10,0 & 247,00 & Presença & 0,54 & 2,70 \\
\hline Mandassaia III & 338,50 & 0,05 & 0,2 & Presença & 8523,00 & 5,0 & 6800,00 & Presença & 0,10 & 0,14 \\
\hline
\end{tabular}

Fonte: Adaptado do ITEP (ITEP, 2015) 
Tabela 1 - Resultados das análises em Poços Profundos das comunidades de Riachão do Jacuípe

(Conclusão)

\begin{tabular}{|c|c|c|c|c|c|c|c|c|c|c|}
\hline Nome Categoria & $\begin{array}{c}\text { Nitratos } \\
\text { mg NO30N/L }\end{array}$ & $\begin{array}{l}\text { Nitritos } \\
\text { mg/L N }\end{array}$ & pH & $\begin{array}{l}\text { Potássio } \\
\text { Total }\end{array}$ & $\begin{array}{l}\text { Sílica To- } \\
\text { tal Reativa }\end{array}$ & $\begin{array}{l}\text { SDT } \\
\mathrm{mg} / \mathrm{L}\end{array}$ & $\begin{array}{l}\text { Sódio To- } \\
\text { tal } \mathrm{mg} / \mathrm{L}\end{array}$ & $\begin{array}{l}\text { Sulfatos } \\
\mathrm{mg} \mathrm{SO4/L}\end{array}$ & Temperatura ${ }^{\circ} \mathbf{C}$ & $\begin{array}{c}\text { Turbidez } \\
\text { UT }\end{array}$ \\
\hline Meta do Parâmetro & 10 & 1 & 6,0 a 9,5 & & & 1000 & 200 & 250 & & 5 UT \\
\hline Mandassaia II & 29,24 & 0,006 & 6,82 & 14,6 & 82,18 & 4800,00 & 895,00 & 217,00 & 28,5 & 0,5 \\
\hline Salgado & 0,23 & 0,006 & 6,90 & 18,3 & 85,05 & 5950,00 & 960,00 & 228,00 & 27,5 & 0,3 \\
\hline Caldeirão Grande & 0,23 & 0,006 & 7,38 & 8,8 & 103,26 & 3082,00 & 815,00 & 109,00 & 28,5 & 28,8 \\
\hline Bom Viver & 16,43 & 0,006 & 7,90 & 3,1 & 59,79 & 1015,50 & 362,00 & 66,36 & 28,5 & 0,3 \\
\hline Ponto Novo & 40,04 & 0,006 & 7,15 & 11,8 & 30,74 & 4463,50 & 1066,00 & 198,00 & 26,8 & 0,3 \\
\hline Mandassaia I & 32,60 & 0,006 & 7,97 & 2,55 & 80,42 & 1448,00 & 302,00 & 80,94 & 27,5 & 0,3 \\
\hline Poções/Capinas & 85,32 & 0,006 & 6,67 & 20,20 & 43,85 & 12992,00 & 1965,00 & 699,00 & 27,4 & 0,56 \\
\hline Baixa Nova & 53,37 & 0,006 & 6,57 & 19,95 & 142,37 & 7363,00 & 508,00 & 223,00 & 28,9 & 19,4 \\
\hline São Francisco & 46,41 & 0,006 & 6,84 & 12,95 & 159,08 & 8765,00 & 1180,00 & 296,00 & 29 & 0,3 \\
\hline Onça & 13,82 & 0,28 & 6,63 & 21,45 & 184,09 & 6981,00 & 804,00 & 48,63 & 29,8 & 0,3 \\
\hline Licuri & 23,84 & 0,006 & 7,36 & 5,60 & 162,90 & 1771,50 & 563,00 & 69,08 & 29,6 & 1,76 \\
\hline Mandassaia III & 195,00 & 0,006 & 7,27 & 19,00 & 25,62 & 7520,50 & 2440,00 & 435,00 & 27,8 & 4,58 \\
\hline
\end{tabular}

Fonte: Adaptado do ITEP (ITEP, 2015) 


\section{4 ÍNDICES DE QUALIDADE DE ÁGUA}

Os índices de qualidade de água podem ser definidos como uma técnica de classificação que fornece a influência da combinação de parâmetros individuais na qualidade global da água (SADAT-NOORI; EBRAHIMI; LIAGHAT, 2013).

Recomendam-se alguns critérios para a seleção do índice a ser utilizado. $O$ primeiro cuidado é quanto à disponibilidade de dados para a aplicação do índice. Não é indicado escolher um índice para o qual não se tenha todos os parâmetros, não se aconselha aferir qualidade a parâmetros não medidos. Por este motivo, caso não se disponha de todas as análises, a melhor solução é não utilizar o índice, ou optar por uma formulação flexível na seleção dos parâmetros. Os métodos CCME WQI (CCME, 2001) e e-IQUAS (ALMEIDA, 2012) têm esta característica, enquanto que o IQA CETESB (CETESB, 2019) exige resultados de nove parâmetros.

Outro cuidado refere-se às atividades humanas desenvolvidas na área de influência do compartimento hídrico a ser avaliado. Para que o índice reflita as condições às quais a água está submetida é necessário contemplar parâmetros que indiquem as alterações relacionadas às atividades, e ao compartimento que está sendo avaliado. O e-IQUAS integra essas condições e pode ser adaptado facilmente aos dois compartimentos, superficial e subterrâneo.

Neste trabalho optou-se por avaliar a qualidade da água utilizando-se três índices, que convergem algumas das caracteríticas exigidas para uma boa avaliação. Foram escolhidos o IQA CETESB (CETESB, 2019), o CCME WQI (CCME, 2001) e eIQUAS (ALMEIDA, 2012). Ou seja, para cada uma das amostras disponíveis (doze poços) foram calculados os três índices de qualidade de água.

\subsection{IQA CETESB}

Um dos primeiros índices para qualificar águas foi criado no primeiro ano da década de 1970, por um grupo de pesquisadores coordenados por Robert M. Brown, com o apoio da National Sanitation Foundation (NSF, 2004). O NSF WQI é amplamente utilizado para representar a qualidade da água em geral devido a simplicidade de sua formulação e a acessibilidade dos parâmetros (HAMDAN; DAWOOD; NAEEM, 2018). Todavia, se mostra inadequado quando aplicado em regiões sob a influência de atividades agrícolas extensivas ou atividades industriais 
que utilizem o corpo hídrico para lançamento dos efluentes. Ademais, a existência de parâmetros mais voltados ao compartimento superficial, obriga que sejam feitas adaptações ao ser aplicado às águas subterrâneas.

Em 1975, a Companhia Ambiental do Estado de São Paulo - CETESB, fez adaptações ao NSF WQI e desenvolveu o IQA - Índice de Qualidade de Água. Desde então, o IQA CETESB é utilizado para prestar informações básicas sobre a qualidade das águas superficiais no Estado de São Paulo e amplamente adotado na maioria das unidades da federação para comunicar a qualidade das águas brutas (ANA, 2012). Trata-se de um índice que avalia a condição de utilização da água bruta para fins de abastecimento público, levando em consideração um tratamento convencional.

As adaptações da CETESB levaram em conta a substituição de variáveis de qualidade, como também mudanças no peso relativo de alguns parâmetros como: coliformes termotolerantes, DBO e pH. O Nitrato foi substituído por Nitrogênio total, englobando nitrito, nitrato e nitrogênio orgânico. As curvas médias de variação de qualidade da água foram mantidas, para as variáveis que não foram substituídas. Essas curvas compatibilizam o valor do resultado encontrado por meio dos testes, e a implicação ocasionada pela presença do parâmetro no corpo hídrico (WEINBERG, 2013).

A Tabela 2 mostra os parâmetros e respectivos pesos propostos pelo IQACETESB.

Tabela 2 - Parâmetros e Pesos do IQA - CETESB

\begin{tabular}{lcc}
\multicolumn{1}{c}{ Parâmetros analíticos } & Unidade de Medida & Pesos Cetesb $\left(\mathbf{w}_{\mathbf{i}}\right)$ \\
\hline Coliformes termotolerantes & $\mathrm{NMP} / 100 \mathrm{ml}$ & 0,15 \\
Demanda bioquímica de oxigênio & $\mathrm{mg} / \mathrm{L} \mathrm{O}_{2}$ & 0,10 \\
Oxigênio dissolvido & $\%$ Saturação & 0,17 \\
Nitrogênio total & $\mathrm{mg} / \mathrm{L}$ & 0,10 \\
Fósforo total & $\mathrm{mg} / \mathrm{L}$ & 0,10 \\
Sólidos totais & $\mathrm{mg} / \mathrm{L}$ & 0,08 \\
pH & - & 0,12 \\
Temperatura da amostra & $\stackrel{\circ}{ }$ & 0,10 \\
Turbidez & $\mathrm{uT}$ & 0,08 \\
\hline
\end{tabular}

Fonte: Adaptado de PQNA (2017)

O cálculo do IQA é feito por meio do produto ponderado dos nove parâmetros e aplicação na seguinte fórmula:

$$
\text { IQA }=\prod_{i=1}^{n} q_{i}{ }^{w}
$$


Onde:

IQA - Índice de Qualidade da Água;

$q_{i}$ - qualidade do i-ésimo parâmetro;

$W_{i}$ - peso recorrente ao i-ésimo parâmetro fixado em função da sua importância para a conformação global da qualidade.

O valor de qualidade do parâmetro (qi) é encontrado por meio da análise do gráfico das curvas médias de variação dos parâmetros, em função da concentração ou do valor medido. As faixas de qualidade adotadas estão na Tabela 3 (ANA, 2012).

Tabela 3 - Qualidade da Água descrita pelo IQA CETESB

\begin{tabular}{llr}
\hline \multicolumn{1}{c}{ Valor do IQA } & \multicolumn{1}{c}{ Classe } & \multicolumn{1}{c}{ Significado } \\
\hline $79<$ IQA $\leq 100$ & ÓTIMA & Águas apropriadas para tratamento convencional vi- \\
$51<$ IQA $\leq 79$ & BOA & sando o abastecimento público \\
$36<$ IQA $\leq 51$ & REGULAR & \\
$19<$ IQA $\leq 36$ & RUIM & Águas impróprias para tratamento convencional vi- \\
IQA $<$ ou $\leq 19$ & PÉSSIMA & sando o abastecimento público, sendo necessá- \\
& & rios tratamentos mais avançados. \\
\hline
\end{tabular}

Fonte: Ana, 2012 (apud CETESB, 2008)

\subsection{CCME WQI}

O NSF WQI e o seu procedente IQA CETESB não admitem a inclusão de novos parâmetros. Outros métodos são flexíveis em acomodar novas variáveis, permitindo que sejam incluídos ou descartados parâmetros. O método apresentado pelo Canadian Council of Ministers of the Environment - CCME WQI é uma dessas ferramentas (CCME, 2001).

Essa versatilidade é uma característica que o diferencia, pois os parâmetros podem ser escolhidos de acordo com o objetivo para o qual se calcula o índice, a importância do parâmetro, como também a disponibilidade de dados. Além disso, o CCME WQI também é adaptável quanto ao período de coleta e ao corpo hídrico. Recomendam-se no mínimo quatro parâmetros e que sejam monitorados em quatro campanhas de amostragem (CCME, 2001).

O CCME WQI é largamente utilizado no país de origem para caracterizar a qualidade das águas superficias e subterrâneas, como também em outras regiões. Foi 
adotado para uso no âmbito do Programa das Nações Unidas para o Meio Ambiente em três formas: o Índice Global de Qualidade da Água Potável (Global Drinking Water Quality Index), um Índice de Qualidade da Água para a Saúde (Health Water Quality Index) e seu Índice de Qualidade da Água Aceitável (Acceptability Water Quality Index) (CCME, 2017). No Brasil, o CCME WQI, tem sido aplicado tanto de forma isolada (LIMA et al, 2011) como em associação com outras ferramentas (ALMEIDA e OLIVEIRA, 2013).

A estrutura do CCME WQI é baseada na frequência de falhas relativas da condição da água estudada, com base no padrão de qualidade da água determinado pela legislação. $O$ índice é composto por três fatores, que assumem valores entre $0 \mathrm{e}$ 100, o cálculo é combinado para criar um vetor, cujo comprimento varia nesse intervalo. Esse vetor tem o valor de 100 subtraído de sua "norma" (ou módulo, que representa o comprimento do vetor), para produzir um resultado próximo de 0 , caracterizando a qualidade da água como muito ruim, e perto de 100 para qualidade excelente (CCME, 2001).

Os fatores simulam a abrangência do impacto causado por uma não conformidade (Alcance), a frequência em que ocorre a não conformidade (Frequência) e a amplitude da não conformidade, referente à diferença de valor de cada parâmetro ao limite de referência (Amplitude) (ALMEIDA, 2012). Os cálculos do alcance e da frequência são relativamente simples, já a amplitude exige um número maior de operações.

\section{Cálculo do alcance (F1):}

O alcance reproduz, em percentual, a quantidade de parâmetros não conformes aos padrões estabelecidos, ao menos uma vez no período da análise, referente a todos os parâmetros medidos (CCME, 2001).

$$
F 1=\left(\frac{\text { Númerodeparâmetrosnãoconformes }}{\text { Númerodeparâmetrosmedidos }}\right) \times 100
$$

\section{Cálculo da frequência (F2):}

A frequência representa a porcentagem individual de testes que não atenderam aos objetivos (CCME, 2001).

$$
F 2=\left(\frac{\text { Númerodeanálisesnãoconfomes }}{\text { Númerodeanálisesrealizadas }}\right) \times 100
$$




\section{Cálculo da amplitude (F3):}

Representa a amplitude das falhas dos parâmetros analisados que não alcançaram o valor estabelecido para seu limite de referência. Esse cálculo é executado em três passos (CCME, 2001):

Cálculo das discrepâncias $(\Delta)$ : o valor que o parâmetro é maior que o padrão estabelecido ou menor quando se trata de valores mínimos (CCME, 2001).

$$
\begin{aligned}
& \Delta=\left(\frac{\text { Valortestadonãoconforme }}{\text { Valorobjetivo }}-1\right), \text { quando o valor não deve ultrapassar o padrão; } \\
& \Delta=\left(\frac{\text { Valorobjetivo }}{\text { Valortestadonãoconforme }}-1\right), \text { quando o valor não deve ser inferior ao padrão; }
\end{aligned}
$$

Em seguida é realizada a soma normatizada da quantidade de análises não conformes, o somatório das discrepâncias (snd) e o resultado é dividido pelo número de análises realizadas (CCME, 2001).

$$
\sum \Delta=\frac{\sum_{i=1}^{n} \cdot \Delta i}{\text { Númerototaldeanálises }}
$$

A amplitude (F3) é então calculada por uma função assintótica, escalonando a soma das discrepâncias $(\Sigma \Delta)$, com o objetivo de se obter uma variação entre 0 e 100 (CCME, 2001).

$$
F 3=\left(\frac{\sum \Delta}{0,01 x \sum \Delta+0,01}\right)
$$

Realizado o cálculo do alcance ( $F$ 1), frequência $(F 2)$ e da amplitude (F3), o índice é calculado pela soma vetorial destes fatores, ou seja, a soma dos quadrados de cada é igual ao quadrado do índice. Essa abordagem trata o índice como um espaço tridimensional que é definido por cada fator ao longo de um eixo. Desta forma, o índice altera proporcionalmente de acordo com as mudanças nos três fatores (CCME, 2001).

$$
\text { IQAccme }=100-\left[\frac{\sqrt{(F 1)^{2}+(F 2)^{2}+(F 3)^{2}}}{1,732}\right]
$$


Na equação do CCME WQI o divisor 1,732 é obtido pela variação de cada fator, que pode variar de 0 até 100 , sendo 100 o comprimento máximo que o vetor pode atingir (CCME, 2001). Com os resultados encontrados por meio do cálculo do índice, as águas podem ser classificadas em cinco categorias, auxiliando a análise (Tabela 4).

Tabela 4 - Qualidade da Água Bruta descrita pelo CCME - WQI

\begin{tabular}{|c|c|c|c|c|}
\hline Categoria & $\begin{array}{r}\text { Faixa de } \\
\text { valor }\end{array}$ & $\begin{array}{c}\text { Qualidade da } \\
\text { Água }\end{array}$ & $\begin{array}{l}\text { Ameaça de } \\
\text { Impacto }\end{array}$ & Condições da Água \\
\hline Excelente & $95-100$ & Protegida & Ausente & $\begin{array}{c}\text { Muito próxima dos níveis } \\
\text { naturais }\end{array}$ \\
\hline Bom & $80-94$ & Protegida & Pequeno grau & $\begin{array}{c}\text { Raramente divergem dos } \\
\text { níveis naturais ou dese- } \\
\text { jáveis }\end{array}$ \\
\hline Mediana & $65-79$ & $\begin{array}{c}\text { Normalmente é } \\
\text { protegida }\end{array}$ & $\begin{array}{l}\text { Ocasionalmente } \\
\text { ameaçada ou } \\
\text { danificada }\end{array}$ & $\begin{array}{c}\text { Às vezes afastam-se dos } \\
\text { níveis naturais deseja- } \\
\text { dos }\end{array}$ \\
\hline Marginal & $45-64$ & $\begin{array}{c}\text { Frequentemente } \\
\text { ameaçada ou } \\
\text { prejudicada }\end{array}$ & $\begin{array}{c}\text { Frequentemente } \\
\text { ameaçada ou } \\
\text { prejudicada }\end{array}$ & $\begin{array}{c}\text { Frequentemente afastam- } \\
\text { se dos níveis naturais } \\
\text { ou desejáveis }\end{array}$ \\
\hline Ruim & $0-44$ & $\begin{array}{l}\text { Quase sempre } \\
\text { ameaçada ou } \\
\text { prejudicada }\end{array}$ & $\begin{array}{l}\text { Quase sempre } \\
\text { ameaçada ou } \\
\text { prejudicada }\end{array}$ & $\begin{array}{c}\text { Geralmente afastam-se dos } \\
\text { níveis naturais ou dese- } \\
\text { jáveis }\end{array}$ \\
\hline
\end{tabular}

Fonte: Adaptado de CMME (2017)

Os pesquisadores alertam que a atribuição do valor do WQI CCME a essas categorias é um processo crítico, mas um tanto subjetivo, uma vez que a categorização baseia-se nas melhores informações disponíveis, no julgamento de especialistas e nas expectativas do público em geral quanto à qualidade da água (CCME, 2017). Vale ressaltar que a avaliação das condições e ameaças aos compartimentos subterrâneos deve ser complementada por outras abordagens da hidrogeologia.

\section{3e-IQUAS}

O Índice de Qualidade de Uso da Água Subterrânea - e-IQUAS, tal como o CCME WQI, admite a inclusão de parâmetros, entretanto não faz recomendações sobre o número mínimo de campanhas.

A determinação do e-IQUAS para um grupo de amostras compreende quatro etapas. A primeira delas consiste da seleção dos parâmetros a serem amostrados e sua vinculação a determinado "grupo de alteração", ou seja, ao agrupamento de 
parâmetros cuja presença produz efeitos similares de mudança na qualidade da água (Agrotóxicos e Pesticidas, Elementos Filtráveis e Partículas, Matéria Orgânica e Nutriente, Micro-organismos, Micropoluentes Minerais, Micropoluentes Orgânicos, Mineralização e Salinidade e PCB (Bifenil Policlorados)).

A associação dos parâmetros aos grupos de alteração baseia-se em indicações de concentrações de solutos não presentes no estado natural das águas subterrâneas: (micro-poluentes orgânicos e minerais) ou claramente identificados como resultado de determinadas atividades humanas quando está acima dos limites conhecidos: (nitrato e praguicidas), e usa como referência estudos do sistema francês de avaliação da qualidade das águas subterrâneas (Système d'évaluation de la Qualité des Eaux Souterraines) (CADILHAC e ALBINET, 2003).

Uma vez identificado o grupo de alterações, categoriza-se a concentração do parâmetro função do teor da substância (Tabela 5), atribuindo-se uma nota a cada parâmetro medido na amostra.

Tabela 5 - Categorias de parâmetros em face de concentração na amostra

\begin{tabular}{ccccc}
\hline Categoria & Concentrações $(\mathbf{n})$ & Nota & Qualificação & Semáforo \\
\hline 1 & $\begin{array}{c}\text { Concentrações abaixo de um valor de re- } \\
\text { ferência (C1) }\end{array}$ & 80 & Ótima & Ótima \\
2 & $\begin{array}{c}\text { Concentrações entre os valores de rele- } \\
\text { vância (C1 e C2) }\end{array}$ & 60 & Boa & Boa \\
3 & $\begin{array}{c}\text { Concentrações entre os valores de rele- } \\
\text { vância (C2 e C3) }\end{array}$ & 40 & Regular & Regular \\
4 & $\begin{array}{c}\text { Concentração acima do valor máximo ad- } \\
\text { missível (C3) }\end{array}$ & 20 & Ruim & Ruim
\end{tabular}

Fonte: Almeida (2012)

Na terceira etapa estabelece-se a nota de cada um dos "Grupos de Alteração", atribuindo-se ao grupo a menor nota obtida pelos parâmetros nele inscritos. Tem-se:

$$
N(G j)=\min [N(P 1), N(P 2), N(P 3) \ldots N(P n)]
$$

Onde:

$$
\begin{gathered}
N(G j)=i \text { - ésimoparâmetro } \\
G j=j-\text { ésimogrupodealterações } \\
N(P i)=\text { notadoi - ésimoparâmetro } \\
P i=i \text { - ésimoparâmetro }
\end{gathered}
$$


E finalmente, a nota do Índice de Qualidade de Uso da Água Subterrânea é conferida pela menor nota entre os Grupos de Alteração, um número adimensional que exprime a qualidade da água.

$$
e-I Q U A S=\min [N(G 1), N(G 2), N(G 3) \ldots N(G n)]
$$

O resultado da fórmula do e-IQUAS, exposta acima, resultará em um valor adimensional, com os possíveis valores 20, 40, 60, 80 (Tabela 6).

Tabela 6 - Qualidade da Água descrita pelo CCME - WQI

\begin{tabular}{ccc}
\hline e-IQUAS & Qualificação & Semáforo \\
\hline 80 & Ótima & Azul \\
60 & Boa & Verde \\
40 & Regular & Laranja \\
20 & Ruim & Vermelho \\
\hline
\end{tabular}

Fonte: Almeida (2012)

\section{RESULTADOS E DISCUSSÃO}

\subsection{Aplicação dos Índices de Qualidade de Água}

O relatório de qualidade da água dos poços profundos da Região de Riachão do Jacuípe (BA) apresenta 25 parâmetros de características diferenciadas, o que dificulta a aquisição de informações consolidadas a partir da simples confrontação entre as análises físico-químicas e bacteriológicas e os padrões estabelecidos.

A caracterização da qualidade da água por meio dos Índices de Qualidade de Água agrupa esses parâmetros, de diferentes unidades e dimensões, em uma escala comum, de maneira a fornecer um número adimensional que define a qualidade da amostra. Foram utilizadas três formulações: IQA CETESB, WQI CCME e e-IQUAS, já mencionadas.

Para usar a metodologia de cálculo do IQA - CETESB foram necesárias algumas adaptações à proposta original, em razão da indisponibilidade das análises de OD, DBO, Nitrogênio Total e Temperatura. Assim, utilizou-se o mesmo ajuste adotado pela ANA (2012), ou seja, calculou-se o índice com os sete parâmetros 
disponíveis, sendo o peso dos parâmetros ausentes redistribuídos entre os demais parâmetros. A Tabela 7 mostra os parãmetros e seus respectivos pesos. Para este índice todas as amostras foram enquadradas com qualidade "ruim".

Tabela 7 - Parâmetros e Pesos do IQA - CETESB Ajustado

\begin{tabular}{lcc}
\hline Parâmetros analíticos & Unidade de Medida & Pesos $\left(\mathbf{w}_{\mathbf{i}}\right)$ \\
\hline Coliformes termotolerantes & $\mathrm{NMP} / 100 \mathrm{ml}$ & 0,15 \\
Fósforo total & $\mathrm{mg} / \mathrm{L}$ & 0,10 \\
Nitrato & $\mathrm{mg} / \mathrm{L}$ & 0,10 \\
Nitrito & $\mathrm{mg} / \mathrm{L}$ & 0,10 \\
$\mathrm{pH}$ & - & 0,12 \\
Sólidos totais & $\mathrm{mg} / \mathrm{L}$ & 0,08 \\
Turbidez & $\mathrm{UT}$ & 0,08 \\
\hline
\end{tabular}

Fonte: Adaptado de PQNA (2017)

O cálculo do CCME WQI obtido a partir dos resultados intermediários dos fatores F1, F2 e F3, apresentou como resultados finais valores que qualificam as águas entre "mediana" e "ruim". Para este índice, a falta de outras campanhas pode interferir no fortalecimento do resultado, pois, neste cálculo, o alcance ou percentual de parâmetros com falha $(\mathrm{F} 1)$ foi igual à frequência ou percentual de análises falhas (F2). Ou seja, a presença de dados coletados em outros períodos do ano ampliaria o alcance, além do que consideraria eventualidades, como as contribuições dos períodos chuvosos e estiagem, colaborações antrópicas, dentre outros.

$\mathrm{Na}$ aplicação do e-IQUAS, como proposto na formulação, foi utilizado o método do operador mínimo para calcular a nota dos grupos de alteração aos quais estavam condicionados os dez parâmetros disponíveis: Micro organismos (CTE e E.Coli), Elementos Filtráveis e Partículas (Ferro e Turbidez), Micropoluentes Minerais (Alumínio), Matéria Orgânica e Nutriente (Nitrito e Nitrato), Mineralização e Salinidade (Cloreto, Sódio, Sulfato, pH, Sólidos totais dissolvidos). Foi gerado um subíndice para cada grupo de alterações, e o índice final (e-IQUAS), foi definido como a menor nota entre todos os subíndices. Com os resultados do e-IQUAS todos os poços foram qualificados como "ruim". Observe-se que, do ponto de vista conceitual o e-IQUAS permite avaliar qualquer amostra independentemente da quantidade de parâmetros, sem comprometer o resultado. Todavia, apesar desta flexibilidade, a seleção dos grupos de alteração tem papel fundamental na representação dos resultados. Reconhecer a influência das atividades realizadas na região de estudo é imprescindível para seleção de parâmetros representativos de cada grupo. 
Segue uma síntese dos resultados. Na Tabela 8 estão relacionados os parâmetros por metodologia de cálculo, e na Tabela 9 estão os resultados dos índices de qualidade da água obtidos nas três metodologias. Observe-se que a aplicação de três metodologias diferentes implica em parâmetros diferentes, e a influência de cada um deles sobre o resultado final pode variar a cada método. Entretanto esta característica não invalida os cálculos, antes contribui para respaldar a utilização dos índices como representação da qualidade da água.

\begin{tabular}{lccc}
\multicolumn{4}{c}{ Tabela 8 - Parâmetros utilizados por Índice de Qualidade de Água } \\
\hline Parâmetros / Índices & CETESB & CCME & e-IQUAS \\
\hline Coliformes termotolerantes & $\mathrm{X}$ & & $\mathrm{X}$ \\
Escherichia Coli & & $\mathrm{X}$ & $\mathrm{X}$ \\
Alumínio & & $\mathrm{X}$ & \\
Amônia & & $\mathrm{X}$ & $\mathrm{X}$ \\
Cloreto & & $\mathrm{X}$ & \\
Cor & & $\mathrm{X}$ & \\
Dureza & $\mathrm{X}$ & & \\
Fósforo & & $\mathrm{X}$ & $\mathrm{X}$ \\
Ferro & & & \\
Fluoreto & & & \\
Manganês & & & \\
Mercúrio & & $\mathrm{X}$ & $\mathrm{X}$ \\
Nitrato & $\mathrm{X}$ & $\mathrm{X}$ & $\mathrm{X}$ \\
Nitrito & $\mathrm{X}$ & $\mathrm{X}$ \\
pH & $\mathrm{X}$ & $\mathrm{X}$ & $\mathrm{X}$ \\
Sódio & & $\mathrm{X}$ & $\mathrm{X}$ \\
Sólidos totais & $\mathrm{X}$ & $\mathrm{X}$ & $\mathrm{X}$ \\
Sulfatos & & $\mathrm{X}$ & $\mathrm{X}$ \\
Temperatura & & $\mathbf{1 2}$ & $\mathbf{1 1}$ \\
Turbidez & $\mathrm{X}$ & \\
Parâmetros Analisados & $\mathbf{7}$ & & \\
\hline Fonte:Etabracaopropia & & & \\
\hline
\end{tabular}

Fonte: Elaboração própria (2019)

A aplicação dos três índices trouxe resultados convergentes, ou seja, não são observadas diferenças significativas nos resultados. As três metodologias confluíram em classificar as águas dos poços de Riachão do Jacuípe como extremas. Excetuando-se o CCME WQI, que agrupou 58\% das amostras na categoria mais crítica ('ruim'), os demais índices utilizados apresentaram 100\% das amostras com resultados como 'ruim', embora para o IQA CETESB esta qualificação não seja extrema (tem-se a categoria péssima). No índice IQA CETESB a desqualificação das 
amostras se deu principalmente pela presença dos microorganismos e teores acentuados de materiais orgânicos e nutrientes (representados pelo nitrito e nitrato). O e-IQUAS e WQI CCME também refletiram esses parâmetros, ademais evidenciam a forte mineralização e salinidade.

Tabela 9 - Comparativo dos Índices de Qualidade da Água das Comunidades

\begin{tabular}{lllllll}
\hline Comunidade/Índices & \multicolumn{2}{c}{ CETESB } & \multicolumn{2}{c}{ CCME } & \multicolumn{2}{c}{ e-IQUAS } \\
\hline Mandassaia II & 24,4888 & Ruim & 49,77179 & Marginal & 20 & Ruim \\
Salgado & 30,9535 & Ruim & 50,97789 & Marginal & 20 & Ruim \\
Caldeirão Grande & 27,8849 & Ruim & 44,48346 & Ruim & 20 & Ruim \\
Bom Viver & 26,8114 & Ruim & 78,63835 & Mediana & 20 & Ruim \\
Ponto Novo & 27,6472 & Ruim & 49,47748 & Marginal & 20 & Ruim \\
Mandassaia I & 27,4498 & Ruim & 62,82774 & Marginal & 20 & Ruim \\
Poções/Capinas & 22,5923 & Ruim & 36,35971 & Ruim & 20 & Ruim \\
Baixa Nova & 23,8955 & Ruim & 35,43904 & Ruim & 20 & Ruim \\
São Francisco & 25,8103 & Ruim & 39,30839 & Ruim & 20 & Ruim \\
Onça & 26,1806 & Ruim & 42,82211 & Ruim & 20 & Ruim \\
Licuri & 24,0476 & Ruim & 60,26483 & Marginal & 20 & Ruim \\
Mandassaia III & 21,3975 & Ruim & 35,12607 & Ruim & 20 & Ruim \\
\hline
\end{tabular}

Fonte: Próprio autor (2018)

Ao coligir os resultados dos três índices, a comunidade de Mandassaia III foi enquadrada com a situação mais crítica para a qualidade da água do poço comunitário. Por este motivo foi escolhida como objeto do estudo sobre a percepção das condições acesso a água.

\subsection{Percepção dos moradores face às condições de acesso à água}

De acordo com dados da Diretoria de Política e Planejamento Ambiental (DIPPA), da Secretaria do Meio Ambiente do Estado da Bahia (SEMA), a comunidade rural de Mandassaia III conta com 170 famílias. Dessas, foram entrevistados 92 responsáveis pelo núcleo familiar, que representa cerca de $50 \%$ do total de domicílios. Vinte e oito (30\%) responderam que utilizam o poço comunitário como principal fonte de abastecimento, enquanto 42 famílias (46\%) fazem uso de cisternas, 22 famílias (24\%) usam outros meios e uma residência é abastecida por poço particular.

A investigação prosseguiu considerando apenas as famílias que usam o poço comunitário, ou seja, 28 famílias. Para este grupo foram abordados aspectos relacionados às condições de uso da água. 
O Gráfico 1 mostra que vinte e quatro chefes de família, ou seja, $86 \%$ relataram que utilizam a água do poço para fins nobres, enquanto que o restante (14\%) faz usos não potáveis. Ademais, se observa que $36 \%$ daqueles que usam a água para fins potáveis não realizam nenhum tipo de tratamento (5 respondentes) ou apenas coam a água (5 respondentes). E os demais (74\%) declaram usar tratamentos que são pouco eficazes.

Gráfico 1 - Usos da água e tratamentos adotados

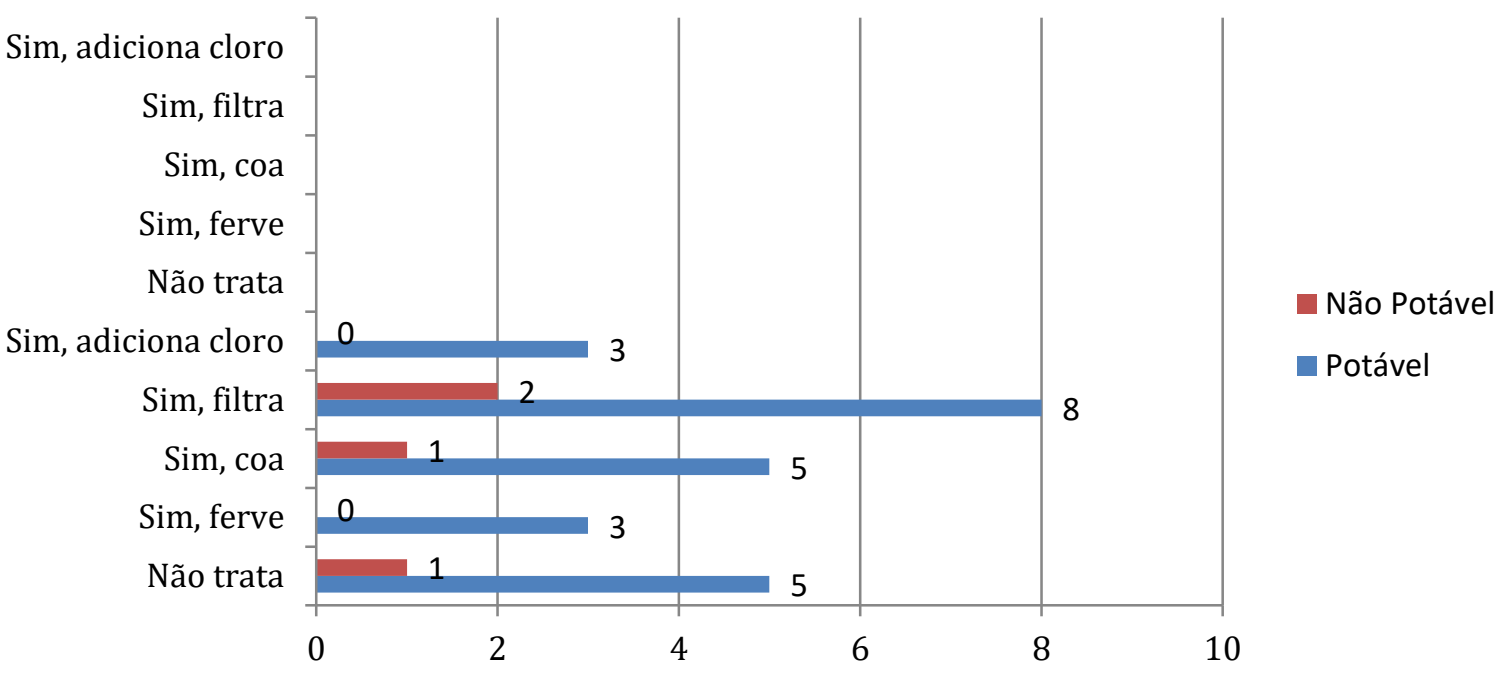

Fonte: Elaboração própria, 2019

\section{Compreensão da pesquisa}

Os dados apontam valores críticos para alguns parâmetros, tal que levaram a água ser classificada como "ruim" pelas três metodologias. Em todas as amostras foi constatada presença de bactérias do grupo coliformes, além de alta concentração de sais. Entretanto ficou evidenciado, nas pesquisas realizadas com os moradores, que esta condição não inibe seu uso para fins potáveis ( $86 \%$ do grupo amostral).

Essas respostas sugerem alguns cenários: os moradores desconhecem a qualidade da água, ou desconsideram os métodos de tratamento, ou ainda, ignoram os riscos do consumo da água de qualidade inadequada.

Para refutar esta situação a população precisa ser informada sobre a qualidade da água que está consumindo, e um dos mecanismos é a divulgação dos índices de qualidade da água. Também precisa conhecer as fragilidades das formas de tratamento e conservação intradomiciliar que utiliza. 
Ademais, são necessárias ações estruturais para melhorias no fornecimento de água, manutenção dos equipamentos existentes, e introdução de tecnologias adequadas à realidade da região.

\section{CONCLUSÕES E RECOMENDAÇÕES}

O Relatório de Teste de Bombeamento (ITEP, 2015), utilizado como fonte de dados para realização deste trabalho, aponta águas com parâmetros cujos teores se distanciam das concentrações naturais desejáveis, não conformes com o estabelecido como aceitáveis para consumo humano, na legislação vigente.

A aplicação de três metodologias de cálculo de Índices de Qualidade de Água (IQA CETESB, CCME WQI e e-IQUAS), mesmo diante das adaptações e restrições adotadas, convergiu em qualificar a maioria das águas como "ruim" e, portanto impróprias ao consumo humano.

Os resultados do presente estudo sugerem que os Índices de Qualidade de Água (IQA's) podem ser considerados como uma ferramenta adequada para a caracterização da qualidade da água e podem ser usados de forma confiável para esse objetivo.

Todavia, algumas considerações são oportunas e evidenciam que estes mecanismos devem ser associados a outros recursos quando se enseja uma avaliação abrangente e definitiva.

Nesse recorte destacam-se águas de qualidade inferior, com vários parâmetros não conformes, cujas características são evidentes em qualquer tipo de avaliação, e, portanto a aplicação dos índices apontaria de maneira inequívoca a baixa pontuação. Contudo, em muitos casos esta situação não é tão explícita, e o índice pode ou não revelar a condição desfavorável. Ou seja, por exemplo, o índice pode incluir parâmetros que, na amostra analisada, apresentaram teores aceitáveis, em detrimento de variáveis que estariam fora do padrão. Deste modo, entende-se que os índices são valiosos, mas devem ser associados a outras ferramentas, e combinados com estudos sobre a realidade local, para adaptações necessárias.

Além disso, a pesquisa evidencia que a população deve ser habilitada a compreender a relação da qualidade da água com possíveis riscos para a saúde. E a disseminação dos Índices de qualidade de água pode ser um mecanismo eficaz nesta 
tarefa, oportunizando a população, gestores e decisores determinarem ações para melhorar os cenários encontrados.

\section{REFERÊNCIAS}

ALMEIDA, G. S., OLIVEIRA, I. B. Avaliação da qualidade das águas do Rio Joanes utilizando o índice IQACCME. Bahia Análise \& Dados, Salvador, v. 23, n. 2, p.369-382, abr./jun. 2013.

ALMEIDA, R. A. S. Índice de qualidade de águas subterrâneas destinadas ao uso na produção de água potável. 2007. 1 v. Dissertação (Mestrado) - Curso de Engenharia Ambiental Urbana, Escola Politécnica, Universidade Federal da Bahia, Salvador, 2007.

ALMEIDA, R. A. S. Índice de Qualidade de Uso da Água Subterrânea (e-IQUAS): Uma Metodologia de Modelagem Numérica Flexível. 2012. 334 f. Tese (Doutorado) - Curso de Engenharia, Escola Politécnica, Universidade Federal da Bahia, Salvador, 2012.

ANA. Panorama de Qualidade das Águas Subterrâneas no Brasil. Superintendência de Planejamento e Recursos Hídricos. Brasília, 2007. ISBN: 978-85-89629-29-4

ANA. Panorama de Qualidade das Águas Superficiais no Brasil. Superintendência de Planejamento e Recursos Hídricos. Brasília, 2012. ISBN: 978-85-8210-007-3

ANA. Conjuntura dos recursos hídricos no Brasil 2018: Informe anual. Brasília, 2018. Disponível em: http://arquivos.ana.gov.br/portal/publicacao/Conjuntura2018.pdf. Acesso em: 27 maio 2019.

BROWN, R.M., McCLELLAND, N. I., DEININGER, R. A.,TOZER, R.G. A Water quality index: Do we dare? Chicago: Water and Sewage Works, 1970, v.117, n.10, p. 339-343

CADILHAC, L. , ALBINET, M. (Coord). Système d'évaluation de la qualité des eaux souterraines - Rapport de présentation, Version 0, Agences de l'eau et le Ministère de l'Ecologie et du Développement Durable, France, 2003. Disponível em: http://rdb.eaurmc.fr/eaux souterraines/fichiers-telechargeables/SEQSOUT0803.pdf. Acesso em: 26 Jul. 2005

CCME (2001) Canadian Council of Ministers of the Environment. Canadian Water Quality. Guidelines for the Protection of Aquatic Life: CCME Water Quality Index 1.0 Users. Manual n. 1288. ISBN: 1-896997-34-1.

CCME (2017). Canadian Council Of Ministers Of The Environment. Canadian environmental quality guidelines: ccme water quality index user's manual. [s. L.]: Canadian Council Of Ministers Of The Environment, 2017. Disponível em: https://www.ccme.ca/files/Resources/water/water quality/WQ1\%20Manual\%20EN.pdf. Acesso em: 28 mar. 2019.

CETESB - Companhia de Tecnologia de Saneamento Ambiental, São Paulo. Índices de qualidade das águas. São Paulo: CETESB, 1975 Disponível em: http://www.cetesb.sp.gov.br/userfiles/file/agua/aguas-superficiais/aguasinteriores/documentos/indices/01.pdf. Acesso em 12 Jan.2011. 
content/uploads/sites/12/2017/11/Ap\%C3\%AAndice-D-\%C3\%8Dndices-de-Qualidadedas-\%C3\%81guas.pdf. Acesso em: 27 maio 2019.

DEININGER, R.A., LANDWEHR, J.M.: A water quality index for public water supplier. Umpublished report. School of Public Health, University Of Michigan, Ann Arbor, 1971.

DINIUS, S. H. Design of an index of water quality. Water Resources Bulletin WARBAQ, v.23, n. 5, p. 833-843, October 1987. 5 fig, 5 tab, 16 ref. Department of the Interior Project A054-ALA - Resumo disponível em http://md1.csa.com/partners/viewrecord.php?reques$\underline{\text { ter }=\text { gs \& collection }=E N V \& \text { recid }=8804284 \& q=\& u i d=789169512 \& \text { setcookie }=\text { yes }}$. Acesso em: 02 Nov. 2006.

HAMDAN, A.; DAWOOD, A; NAEEM, D. Assessement study of water quality index (WQI) for Shatt Al-arab River and its branches, Iraq. Matec Web Conferences, Iraq, v. 1, n. 162, p.1-7, 7 maio 2018. Disponível em: https://www.matecconferences.org/articles/matecconf/pdf/2018/21/matecconf bcee32018 05005.pdf. Acesso em: 16 out. 2018

HORTON, R. K. A índex number system for rating water quality. Journal Water Pollution Control Federation, v. 37, p. 300-305, 1965.

ITEP. Instituto de Tecnologia de Pernambuco. Relatório de teste de bombeamento: Município Riachão do Jacuípe - Mandassaia III. Salvador: Itep, 2015.

LIMA, L.B. S., RIBEIRO, E.V., MAGALHÃES JÚNIOR, A.P., ÍNDICE DE QUALIDADE DA ÁGUA NO BAIXO RIO DAS VELHAS: EXPERIÊNCIA METODOLÓGICA COM IQA CCME, In: SIMPÓSIO BRASILEIRO DE RECURSOS HÍDRICOS, 19., 2011. [Anais...] Disponível em:

https://www.abrh.org.br/SGCv3/UserFiles/Sumarios/8fd209f0f175e20f3d65a835968d67fa 03 3228c006563c230a2debf9ed21861b.pdf. Acesso em: 14.Ago.2015

NSF - NATIONAL SANITATION FOUNDATION. Disponível em: http://www.nsf.org. Acesso em: 15 Ago. 2018.

PEMAPES. Plano estadual de manejo de águas pluviais e esgotamento sanitário, TOMO II - Diagnósticos e Levantamentos - RDS 15 - Bacia do Jacuípe. v.1, SEDUR Secretaria de Desenvolvimento Urbano do Governo do Estado da Bahia. 2011.

PQNA (Brasil). Agência Nacional de Águas. Indicadores de qualidade - índice de qualidade das águas (IQA). 2017. Disponível em: http://pnqa.ana.gov.br/indicadores-indiceaguas.aspx. Acesso em: 02 maio 2019.

ROGERS, W.; BALLANTYNE, A. Populações especiais:vulnerabilidade e proteção. Reciis, [s.l.], v. 2, n. 1, p.31-41, 8 dez. 2008. Fundacao Oswaldo Cruz. http://dx.doi.org/10.3395/reciis.v2.sup1.207pt.

SADAT-NOORI, S. M.; EBRAHIMI, K.; LIAGHAT, A. M.. Groundwater quality assessment using the Water Quality Index and GIS in Saveh-Nobaran aquifer, Iran. Environmental Earth Sciences, [s.I.], v. 71, n. 9, p.3827-3843, 8 set. 2013. Springer Science and Business Media LLC. http://dx.doi.org/10.1007/s12665-013-2770-8. Disponível em: https://link.springer.com/article/10.1007/s12665-013-2770-8. Acesso em: 07 jun. 2019.

SECRETARIA DE RECURSOS HÍDRICOS E AMBIENTE URBANO (Brasil). Ministério do Meio Ambiente. Documento Base Programa Água Doce. Brasília: Mma, 2012. Disponível em: https://aguadoce.mma.gov.br/anexos/documento-base.pdf. Acesso em: 27 maio 2019. 
SERVIÇO GEOLÓGICO DO BRASIL. Projeto cadastro de fontes de abastecimento por água subterrânea: Diagnóstico do Município de Riachão do Jacuípe - Bahia. Salvador: Cprm, 2005. 22 p.

TOMAS, D.; ČURLIN, M.; MARIć, A. S.. Assessing the surface water status in Pannonian ecoregion by the water quality index model. Ecological Indicators, [s.I.], v. 79, p.182-190, ago. 2017. Elsevier BV. http://dx.doi.org/10.1016/j.ecolind.2017.04.033. Disponível em:

https://www.sciencedirect.com/science/article/pii/S1470160X17302108. Acesso em: 16 out. 2018.

WEINBERG, A. Uso de índice de qualidade de água para a caracterização da bacia hidrográfica do guandu. Rio de Janeiro - RJ - UFRJ: Escola Politécnica, 2013. 